\title{
El endeudamiento de Hidalgo
}

\author{
Carlos Herrejón Peredo* \\ EL COLEGIO DE MICHOACÁN
}

El trabajo pretende ser una aportación documentada en la vida del prócer, cuyas facetas como propietario de haciendas y empresario son reveladas en detalle. Simultáneamente, al ubicarse en el parteaguas de los siglos XVIII y XIX, redimensiona las crisis agrícolas del tiempo, así como las políticas financieras de la Corona. Las finanzas de Miguel Hidalgo son descritas como la forma en que aquel criollo pródigo y generoso se procuraba a sí mismo, y a quienes le rodeaban, de algunas de las cosas placenteras de la vida, compartiendo, prestando y regalando con soltura. Más allá de esto se descubre un mundo de relaciones que apuntan a las redes económicas de las clases medias de la región y se aclaran los motivos de decisiones personales, como viajes y traslados de residencia.

(Hidalgo, insurgencia, deudas)

a crisis agrícola de 1785-1786, que azotó el Bajío, había obligado a buscar soluciones como el fomento de cultivos de riego en zonas distantes y de otro clima. Esto se convirtió en prevención para futuros percances. De tal suerte agricultores de esa región, sin dejarla, buscaban poner un pie en otras tierras. Así, el administrador de la hacienda de Corralejo, Cristóbal Hidalgo, que había padecido aquella crisis, ${ }^{1}$ vio con buenos ojos que tres de sus

* peredoch@colmich.edu.mx En su primera versión este trabajo fue presentado en el Congreso México 1808-1821, coordinado por el Dr. Andrés Lira, México, El Colegio de México, 8-10 de noviembre de 2007.

${ }^{1}$ Enrique Florescano y Rodolfo Pastor, Fuentes para la historia de la crisis agricola de 1785-1786 (Selección documental), México, Archivo General de la Nación (en delante AGN), II, pp. 892-893. 
nueve hijos se interesaran en comprar las pequeñas haciendas de Jaripeo, Santa Rosa y San Nicolás al oriente de Michoacán, cerca de Taximaroa. Ellos eran Joaquín, Miguel y Manuel Hidalgo. ${ }^{2}$ Se trataba de una oportunidad, pues se estaban subastando en la ciudad de México, donde vivía Manuel, quien las adquirió por $\$ 18,000$, participando tal vez con la parte más significativa. ${ }^{3} \mathrm{Al}$ poco tiempo, en 1791, los Hidalgo hubieron de conseguir de la mitra vallisoletana un depósito por $\$ 7,000$ a $5 \%$ anual, por cinco años y renovable, para habilitar aquellas haciendas. ${ }^{4}$ Ninguno de ellos las atendió directamente, si bien el propietario formal, que era Manuel, debería estar más al pendiente. ${ }^{5}$ Nombró un administrador, Félix Cardoso Villaseñor, quien no pudo evitar el despojo de una parte de la fincas, si bien pequeña, perpetrado por una autoridad del rumbo. ${ }^{6}$

Es poco probable que los Hidalgo hubieran contado con la liquidez necesaria de los $\$ 18,000$ para aquella compra. Un préstamo por $\$ 2,000$ que por esos días solicitó y obtuvo Joaquín Hidalgo parece

2 Joaquín y Miguel Hidalgo otorgaron poder a su hermano Manuel para adquirir la hacienda de Jaripeo, Valladolid, 3 de febrero de 1787: Ramón Alonso Pérez Escutia, Aspectos de la vida preinsurgente de Hidalgo, Morelia, Universidad Michoacana de San Nicolás de Hidalgo (en adelante UMSNH), 1991, 71-73.

${ }^{3} \mathrm{El} 13$ de diciembre de 1790 se dio la real provisión que asignaba las haciendas a Manuel Hidalgo. El 3 de enero de 1791 Miguel Hidalgo se apersonó a nombre de su hermano Manuel en Taximaroa para solicitar la entrega de las haciendas, que tuvo efecto del 22 al 25 de febrero de 1791: AgN, Tierras, vol. 1219, exp. 2, fs. 1-118. Edmundo O’ Gorman "Hidalgo, litigante. 1791-1793", Boletín del AGN, México, julio-septiembre 1946, t. XVII, núm. 3, 372-379. Posteriormente Manuel Hidalgo estuvo en las haciendas, del 8 al 15 de marzo, a efecto de que se realizara avalúo de las mismas, que fue por \$50,250: Universidad Iberoamericana (en adelante UIA), Biblioteca Francisco Xavier Clavigero, Archivo de don Miguel Hidalgo y su familia, n. 123.

${ }^{4}$ Miguel Hidalgo a nombre de su hermano Manuel solicita y obtiene $\$ 7,000$ de la mitra vallisoletana, 15-17 de junio de 1791. La cantidad se integró así: \$4,000 de la capellanía fundada por María Teresa Ruiz de la Rabia, y \$3,000 de la fundada por Francisco Gutiérrez de Soto: UIA, Archivo de don Miguel Hidalgo y su familia, n. 123. Pérez, Aspectos cit., pp. 126-132.

${ }^{5}$ Después del avalúo Manuel se trasladó de las haciendas a Valladolid donde el 28 de marzo nombró administrador a Félix Cardoso Villaseñor: Pérez, Aspectos cit., pp. 120-123.

${ }^{6}$ Miguel Hidalgo reclama el despojo de una parte de las tierras de su hermano Manuel perpetrado por José Mariano Pérez, encargado de la administración de justicia, a pedimento de Antonio Campos, Tajimaroa 11 de noviembre de 1793: O' Gorman, "Hidalgo Litigante", cit., pp. 378-381. 
se destinó a ello, pero era insuficiente. ${ }^{7}$ En cambio hubo dos operaciones paralelas a los trámites de adquisición de las haciendas de Taximaroa, de cuyos fondos tal vez echaron mano los Hidalgo. Sucedió, en efecto que Josefa Picado, dueña de Corralejo, mediante poder otorgado a Miguel Hidalgo, había solicitado y obtenido de la mitra vallisoletana la cantidad de $\$ 20,000$ supuestamente para habilitación de Corralejo. ${ }^{8} \mathrm{Y}$ posteriormente recibió $\$ 6,000$, gracias a trámites del mismo Miguel. ${ }^{9} \mathrm{Al}$ fin y al cabo, si los Hidalgo tomaron de ese dinero para la compra de las haciendas de Taximaroa, simplemente tendrían que hacer rendir más las tierras de Corralejo, así como pagar en sus tiempos réditos y capital.

Los Hidalgo profesionistas habían ascendido notablemente: Joaquín, de rector del Colegio clerical a cura interino de San Miguel el Grande y de ahí a cura propietario de Tiríndaro-Coeneo y luego cura de Santa Clara. ${ }^{10}$ Manuel, de abogado de la Real Audiencia de Guadalajara pasó a la de México y obtuvo el puesto de abogado de presos de la Inquisición. Otros dos hermanos, José María y Mariano, iniciaron estudios, pero no concluyeron carrera. José María se quedó en Corralejo ayudando a su padre, por cuya muerte en agosto de 1790 quedó como administrador de la hacienda. Por su parte Mariano fue destinado al comercio gracias a un préstamo obtenido por Joaquín. ${ }^{11}$

${ }^{7}$ Joaquín Hidalgo el 23 de febrero de 1787 dio poder a José Agustín de Castro para que en unión de su hermano Miguel Hidalgo solicitara \$2,000 al Juzgado de Testamentos y Capellanías, que en efecto obtuvieron el 5 de marzo de 1787: Pérez, Aspectos cit., pp. 73-83.

${ }^{8}$ Miguel Hidalgo a nombre de Josefa Picado solicitó préstamo de $\$ 20,000$, Valladolid, 7 de marzo de 1787; avalúo de la hacienda por \$172,075, marzo-abril de 1787; fiadores, junio de 1787; autorización del préstamo y escritura de obligación, Valladolid, 4 de julio de 1787: Biblioteca Pública Universitaria, Morelia, (en adelante BPU), Documentos de Hidalgo. Enrique Arreguín, Hidalgo en San Nicolás. Documentos inéditos, Morelia, Fímax, 1956, 53-58. Pérez, Aspectos cit., pp. 83-85.

${ }^{9}$ Otorgamiento de poder, 3 de junio y 30 de septiembre de 1788; solicitud, 30 de julio y 1 de agosto de 1788, octubre de 1788; otorgamiento de préstamo, 6 de octubre de 1788: Pérez, Aspectos cit., pp. 86-92; UiA, n. 99.

${ }^{10}$ Resolución de concurso de beneficios: para curato de Santa Clara del Cobre, José Joaquín Hidalgo: Valladolid, 1 de diciembre de 1787; 21 de abril de 1788; colación, 19 de enero de 1788 .

${ }^{11}$ Fiadores, 8 de agosto y 24 de octubre de 1788: Pérez, Aspectos cit., pp. 99-102. 
Miguel, que había pasado por todas las cátedras del Colegio de San Nicolás, conservando las de teología y moral, llegó a secretario, vicerrector, ${ }^{12}$ tesorero del Colegio y rector. ${ }^{13}$ Todo ello significaba mayores ingresos. Así, por la cátedra de teología percibía $\$ 300$ anuales, por la de moral $\$ 250$, por el puesto de vicerrector, $\$ 100$; de rector, $\$ 300$; por tesorero, un porcentaje de lo que cobraba para el Colegio, que distribuido eran $\$ 303$ al año. De manera que antes de ser rector recibía $\$ 953$ y de rector $\$ 1,153$. Aparte había concursado y obtenido por currículo, la sacristía mayor de Apaseo, un beneficio, que no requería su presencia en el lugar, y le dejaba al año unos $\$ 100$; y luego disfrutó otro tanto de la sacristía de Santa Clara. ${ }^{14}$ Finalmente, gozó una capellanía, que le redituaba también $\$ 100 .{ }^{15}$ De manera que en total los ingresos anuales de Hidalgo siendo rector llegaban a $\$ 1,353$, cantidad nada despreciable, pero inferior a beneficios parroquiales de medianos para arriba. Como sea, el ascenso de los Hidalgo había sido rápido, y además de sus méritos, parece había concurrido la mediación de dos tíos suyos, connotados y bien colocados clérigos del obispado: José Antonio y Vicente Gallaga Villaseñor, primos hermanos dobles de la difunta Ana María Gallaga Villaseñor.

El mejor destino económico para un clérigo de aquel tiempo, fuera de las canonjías, no era la rectoría de un colegio, sino una pa-

Solicitud de préstamo y otorgamiento, 17-20 de octubre de 1788: Archivo Enrique Arreguín (en adelante AEA), caja 17, exp. 9, fs. 473-495, ficha 388.

${ }^{12}$ De 1785 a 1789.

${ }^{13}$ Nombrado tesorero el 27 de enero de 1786; rector el 20 de enero de 1790: Archivo Capitular, Catedral de Morelia (en adelante ACC), Actas de Cabildo, vol. 35, f. 366; vol. 37, f. 48v En ambos puestos duró hasta febrero de 1792.

${ }^{14}$ Resolución de concurso de beneficios: para sacristía de Santa Clara, Miguel Hidalgo, Valladolid, 1 de diciembre de 1787, y 21 de abril de 1788; título y registro, 31 de mayo y 7 de junio de 1788; entrega de Sacristía, 22 de junio de 1788: Archivo Casa de Morelos (en adelante ACM), fondo diocesano, sección gobierno, serie parroquias, subserie vacantes, caja 162, años 1787-1788, exp. 63; BPU, Documentos de Hidalgo. Arreguín, Hidalgo cit., pp. 72-74. UIA, n. 82.

${ }^{15}$ Abad Queipo declara capellanía favor de Miguel Hidalgo 11, 12 y 28 de abril de 1791; Hidalgo demanda sus réditos, abril-mayo de 1791; negativa del Provisor Tapia; insistencia de Hidalgo; anuencia, 7 de febrero de 1792: ACM, fondo diocesano, sección gobierno, serie procesos legales, subserie bienes materiales, caja 81, exp. 56: concurso de Melchor de Ulibarri, fs. 42-47, 60-61. 
rroquia de diezmos y obvenciones significativos. Y Miguel después de entrar a varios concursos, logró en interinato la parroquia de Colima en febrero de 1792. Antes de salir hubo de entregar cuentas de los cinco años en que se había hecho cargo de la tesorería del Colegio. Hizo una relación pormenorizada de los ingresos, que importaron $\$ 59,580.6$, así como de los gastos que fueron $\$ 60,862$, quedando a su favor $\$ 1,282.1{ }^{16}$ Pero antes de su aprobación, las cuentas deberían ser revisadas. Y eso llevaría tiempo.

Por lo pronto Hidalgo llegaba a Colima y calculaba que la parroquia le daría más que los ingresos de San Nicolás, pues por participación en el diezmo tendría alrededor de $\$ 1,250$ anuales y por obvenciones $\$ 2,782$, que en realidad se le reducían a $\$ 1,077$, pues de ellas debía pagar tres vicarios, amanuense y otros gastos. ${ }^{17} \mathrm{De}$ cualquier manera al año serían en total $\$ 2,327$ netos, alrededor de $\$ 1,000$ más de lo que había percibido en San Nicolás. Sin embargo, tales percepciones no eran inmediatas y hubo de gastar en viaje, menaje y servicio de casa cural, sobre lo que no tenía experiencia, pues desde los doce años su residencia había sido el Colegio. Además antes del año se le presentaron los gastos de otro largo viaje, de Colima a San Felipe en la intendencia de Guanajuato, pues por fin se le daba en propiedad un beneficio de primera. Así las cosas, hubo de solicitar y obtener de tres sujetos de la localidad varios préstamos por un total de $\$ 1,650 .{ }^{18}$ Llegó a San Felipe con el año de $1793 .{ }^{19}$

\footnotetext{
${ }^{16}$ Arreguín, A Morelos, pp. 95-96; ACc, Morelia, Actas de Cabildo, vol. 37, sesión del 7 de febrero, f. 276.

${ }^{17}$ Hice el cálculo de obvenciones y deducciones a partir de la relación de 'Emolumentos que ha habido en el curato de la villa de Colima desde el día dos de febrero de este presente año de mil setecientos noventa y dos hasta dos de junio de el mismo año' que incluye la contribución para el colegio de niñas de Valladolid: UIA, n. 132.

${ }^{18}$ Así integrados: \$1000 a María Juliana García: UIA, n. 180; \$150 a la cofradía de la Soledad: Archivo Capitular de Administración Diocesana, Catedral de Morelia (en adelante: $\mathrm{ACAD})$, caja 119 ; y $\$ 600$ a un Gregorio Iriarte, que se obtuvieron así: éstos pertenecían a la cofradía del Santísimo, fueron solicitados a Hidalgo en su calidad de cura, quien con la venia del obispo los dio a Iriarte y acto seguido se los pidió prestados a título personal, Colima, 27 de septiembre, 1, 8, 11 de octubre y 12 de noviembre de 1792: UIA, n. 136; ACAD, caja 119.

${ }^{19}$ Tomó posesión el 24 de enero: Jesús Ibarra Grande, Don Miguel Hidalgo y Costilla y Gallaga, cura de la Villa de San Felipe, Guanajuato, Archivo General del Estado de Guanajuato (en adelante AGEG), 2003, 32-33.
} 
Ahí percibiría anualmente alrededor de $\$ 3,500$ netos. Era un reconocimiento a su desempeño como brillante catedrático y el mejor teólogo del obispado.

Las fincas de Taximaroa pasaron a Miguel en 1794. No estaban produciendo lo que se esperaba, tal vez por mal tiempo o mala administración, o bien porque el depósito no se había empleado totalmente en ellas. Como sea, ese mismo año Miguel solicitó y recibió en depósito hipotecario otros $\$ 8,000$ a cinco años, obligándose a réditos de $\$ 400$ anuales, de nuevo para habilitarlas, ${ }^{20} \mathrm{o}$ tal vez más bien para pagar a su hermano Manuel la parte con que había participado en la compra. De tal manera, a partir de este segundo depósito, Miguel debía pagar anualmente $\$ 750$ de réditos. Figurando ya como dueño de las haciendas, Miguel aprovechó la cercanía de las minas de Angangueo para que en ellas se beneficiaran metales preciosos. ${ }^{21}$ Mas no parece que se haya logrado mayor cosa, al menos que la mina del Espíritu Santo, donde su hermano Joaquín invirtió hacia 1798, se ubicara en Angangueo, y de la que obtuvo $\$ 4,000 . .^{22}$

Independientemente de la falta de producción de las haciendas, sobrevino un problema no menor; y es que Miguel, en la euforia de ser hacendado a distancia y beneficiado de pingüe parroquia, durante los siete primeros años en San Felipe gastó pródigamente en comida, música, baile y teatro para gente de diversas calidades:

${ }^{20}$ Estos $\$ 8,000$ estaban conformados por $\$ 3,000$ de obras pías de la parroquia de Ucareo, $\$ 1,000$ de la testamentaria de Francisco María Morgabi, $\$ 1,000$ de la testamentaría de Carlos Muñoz de Sanabria, \$1,000 de obras pías del Colegio de exjesuitas de Valladolid, \$1,600 de la Colecturía de Ánimas y \$400 de concurso de acreedores de Francisco Lloreda. Constitución de fiadores, José María de la Fuente y José María Lanzagorta, así como poder de Miguel Hidalgo a Nicolás Baquero, San Miguel el Grande, 28 de abril de 1794; otorgamiento del préstamo por Abad Queipo, Juez de Testamentos y Capellanías, 2 de mayo de 1794; Nicolás Baquero recibe cantidad e hipoteca haciendas: Pérez, Aspectos cit., pp. 133-144.

${ }^{21}$ Testimonio de Martín García: Boletín del Archivo General de la Nación, México, III, n. 3, julio-septiembre 1932, 441-451.

${ }^{22}$ Joaquín Hidalgo ante trámites de Francisco Antonio Olaciregui para eximirse como su fiador por $\$ 3,000$, exige que Domingo Larragoiti le pague $\$ 4,000$ de su participación en la mina del Espíritu Santo, 24 de enero de 1799 a 6 de noviembre de 1800: AEA, caja 17, exp. 19, fs. 473-495, ficha 388. 
criollos, indios y castas. Por la igualdad con que trataba a todos, la casa cural de San Felipe sería llamada la Francia Chiquita. ${ }^{23}$

Es también casi seguro que entonces haya comprado libros que siempre quiso tener, como las obras completas de uno de sus teólogos preferidos, Jacobo Jacinto Serry, así como textos de historia a cuya lectura se aficionó en esos años. Finalmente, dadivoso como era, no le duraba el dinero frente a sus parientes necesitados, particularmente los hijos del segundo y tercer matrimonio de su padre: Mariano, Ana Josefa, Juan Nepomuceno, Guadalupe, Vicenta y Agustina Lucía. ${ }^{24}$ Se decía en efecto que había conseguido el beneficio parroquial, "para que socorriera a su pobre familia". ${ }^{25}$

Alguno podría agregar como renglón de egresos el juego de apuesta, ya que hay testimonios. Provienen los más de la misma fuente, Ramón Pérez, comisario de la Inquisición y émulo de Hidalgo como rector del Seminario Tridentino. Dice primero que "se atrasó su salida [de Hidalgo] a beneficios 'acaso por jugador"; luego consigna dos veces lo que dice escuchó al provisor Juan Antonio de Tapia: "juegos, minas, abandono de sus obligaciones, esto hallará usted en él”. E informa, refiriéndose a los años que lo conoció en Valladolid: "digo que fue un jugador de profesión, tan disipado, que tenía abandonado cuanto tenía a su cargo". Mas llama la atención que al inicio del informe el propio Ramón Pérez declara enfáticamente: "jamás lo he tratado de cerca [a Hidalgo], ni me acuerdo haber estado en su vivienda, ni haberle visto en la mía, sino de puro cumplimiento a convidar para alguna función literaria; tampoco he tenido con él conversación alguna”. ${ }^{26} \mathrm{Tal}$ es la fuerza de su testimonio. Otro proviene de José Vicente de Ochoa, quien dice de Hidalgo "haber éste jugado comúnmente aun desde mozo”. Uno más de Francisco Antonio de Unzaga, no

\footnotetext{
${ }^{23}$ Antonio Pompa y Pompa, Procesos inquisitorial y militar seguidos a D. Miguel Hidalgo y Costilla, México, Instituto Nacional de Antropología e Historia, 1960, 74, 96, 106, 80, 83.

${ }^{24}$ Jesús Amaya, El padre Hidalgo y los suyos. Genebiografia del héroe, sus antepasados y parientes, México, Lumen, 1952, 174-182. Cristóbal Hidalgo murió el 31 de agosto de 1790.

${ }^{25}$ Pompa, Procesos cit., p. 54.

${ }^{26}$ Pompa, Procesos cit., pp. 14, 19, 54, 53.
} 
por haberlo visto, sino por otros: "La vida que lleva dicho señor cura me aseguran es una continua diversión, o estudiando historia, a lo que se ha dedicado con empeńo, o jugando o en músicas, pues tiene asalariada una completa orquesta cuyos oficiales son sus comensales y los tiene como de su familia" ${ }^{27}$ Estos datos, vagos en cuanto al juego, reciben alguna precisión de quien lo trató de cerca, Martín García: "Aunque Hidalgo, según supe, antes de salir de Valladolid, estaba entregado al vicio del juego, mas cuando yo fui a San Felipe, no lo tenía, aunque algunas ocasiones lo vide también jugar" ${ }^{28}$ Así, pues, no parece que el gasto de Hidalgo en San Felipe se haya derivado mayormente del juego, sino del dispendio en música y comida para todos, libros para sí mismo y ayuda a parientes. ${ }^{29}$

Pero tales gastos se reflejaron en el atraso de pagos de los réditos referidos y en otros menores que se fueron acumulando hasta hacerse mayores. Me refiero a las pensiones y cargas fiscales que iban aparejadas a los beneficios eclesiásticos del obispado, los cuales debían pagar una contribución para el sostenimiento del Seminario Tridentino y para el Colegio femenino de las Rosas de Valladolid. Y la Corona, imponía la mesada, y a través de la Comisaría de la Bula de la Santa Cruzada exigía un subsidio por la obtención y disfrute de los mismos beneficios. ${ }^{30}$

${ }^{27}$ Pompa, Procesos cit., pp. 68, 74.

${ }^{28}$ Boletin del Archivo General de la Nación, Mexico, III, n. 3, julio-septiembre 1932, 441-451.

${ }^{29}$ Alamán consigna esto otro: "pues, aunque según se dice, el cabildo eclesiástico de Valladolid le franqueó más adelante cuatro mil pesos para los gastos y propinas del grado de doctor, los perdió al juego en Maravatío, al hacer el viaje a México para solicitarlo": Lucas Alamán, Historia de México, I, México, Jus, 1942, 226. Por el contrario, el propio Hidalgo antes de morir aseguró que no se doctoró, porque "cuando intenté verificarlo, lo frustró la muerte de mi padre y después no insistí en hacerlo, porque tomé la resolución de no graduarme porque no pretendía colocación que lo exigiera": Juan E. Hernández y Dávalos, Colección de documentos para la guerra de Independencia de México de 1808 a 1821, I, México, 1877, 190.

${ }^{30}$ De tal manera, como ejemplo, por la pensión conciliar o del Seminario, el párroco de San Felipe debía pagar al año \$96, que en su caso se sumarían a $\$ 9$ anuales más $\$ 3$ de unos meses que quedó a deber de la sacristía de Santa Clara. 
Así empezaron a ser frecuentes los reclamos de los acreedores a Miguel Hidalgo. ${ }^{31}$ Miguel cubría unos pagos, ${ }^{32}$ ignoraba otros, y al final muchos se le juntaban; de tal suerte en 1795 ya se hablaba de concurso de acreedores. Pero tampoco al cura de San Felipe le entregaban un dinero que le debían, pues las mismas autoridades civiles de San Felipe no hacían caso, echando mano, comenta Hidalgo "de los mil medios que aquí encuentran para eludir la justicia”.

A raíz de que su hermano Joaquín obtuvo la parroquia de Dolores y empezó a saldar algunas deudas propias, ${ }^{33}$ también pudo aliviar un crédito vencido de su hermano Miguel, al facilitarle $\$ 1,710.4 .^{34}$ De tal manera se cubrieron algunos réditos caídos, pero no todos.

Por esos mismos días las cuentas de la tesorería de San Nicolás finalmente fueron revisadas por dos veces, en la primera, de 1797, el saldo a favor de Hidalgo se modificó de $\$ 1,282.1$, a sólo $\$ 400.3 .^{35}$ Pero el resultado de la segunda revisión, de 1799 , fue sorprendente: el Colegio no le debía nada, al contrario Hidalgo adeudaba \$7,069.3.

${ }^{31}$ A fines de noviembre de 1794 debía $\$ 12$ de la pensión al Seminario Tridentino por el beneficio de la Sacristía de Santa Clara. Cantidad pequeña y deuda frecuente en no pocos clérigos: BPU, Documentos de Hidalgo, Cuentas producidas por don Nicolás de la Cuesta, tesorero del Real y Pontificio Colegio Seminario. El 11 de febrero de 1795, Hidalgo comunica a Gabriel García de Obeso, administrador o mayordomo de instituciones como de la Bula de la Santa Cruzada y del convento de Santa Catarina, que sólo puede pagarle $\$ 100$, pues "con el motivo de haber sido el año sumamente estéril se halla mi curato tan escaso, que con dificultad me da para mi precisa mantención”: El 22 de abril escribe al mismo que no ha podido enviar $\$ 1,000$ de réditos caídos adeudados a las monjas de Santa Catarina, porque tampoco a él le han entregado dinero, que al parecer se le debía, "de los inventarios de Velarde". El 22 de agosto escribe al mismo diciéndole que el alcalde de primer voto, Joaquín Alderete, quien debe entregarle el dinero de los inventarios de Velarde, se halla ausente, mas espera obtenerlo del otro alcalde. El 23 de septiembre, al mismo, que no quedó de autoridad el alcalde de segundo voto, sino el alguacil, "peor por todos títulos que Alderete, y con esto no hay esperanza": AEA, caja 24, exp. 10, fs. 581-593, ficha 660 .

${ }^{32}$ Pagos de pensión conciliar, 1795-1796: Bup, Documentos de Hidalgo. Arreguín, Hidalgo cit., p. 81. Miguel Hidalgo en 20 de abril de 1796 comunica a García de Obeso que ha abonado \$100 para deuda de \$222 de Las Rosas y que el negocio de Velarde “está silencio", pues el alcalde no asiste en la villa. En diciembre, al mismo, Hidalgo escribe que ya cubrió $\$ 1,000$ de testamentaría de Morgavi y sólo restan $\$ 78$ de rédito, y que las fincas de Velarde ya están en subasta: AEA, caja 24, exp. 10, fs. 581-593, ficha 660.

${ }^{33}$ AEA, caja 17, exp. 9, fs 473-495, ficha 388.

${ }^{34} 11$ y 12 de noviembre de 1796: ACAD 22-0-01-30, p. 376.

${ }^{35}$ UIA, n. 127 , fs. $22 \mathrm{v}-32$. 
Y en realidad las cuentas de Hidalgo no estaban tan mal, pues apenas le encontraron ahí un alcance por \$303.1. La diferencia principal estaba en el criterio del gasto. El segundo contador tuvo por excesivos $\$ 4,512$ de cocina y alimentos; no le parecieron unas condonaciones de pagos de colegiatura por $\$ 422$, y le cobraba $\$ 1,820$ de réditos porque Hidalgo había dispuesto de capitales del Colegio para el gasto corriente. Lo que pasaba es que la segunda revisión era promovida por quien había sido sucesor de Hidalgo en el puesto de rector y tesorero, y había optado por una austeridad contraria a la prodigalidad de Hidalgo, quien entre otras cosas había dispuesto que los estudiantes comieran carne todos los días. Se llamaba Manuel Iturriaga. Al enterarse Hidalgo de tales cargos, manifestó que nombraría apoderado a quien daría instrucciones. ${ }^{36}$

Tenía otros apremios inaplazables. Pues el principal de sus acreedores, el Juzgado de Testamentos y Capellanías, le reclamaba $\$ 1,080$ de réditos caídos, del préstamo de $\$ 8,000$; y como no se tenía esperanza que los pagara, el colector solicitó el embargo de las haciendas al titular del Juzgado, Manuel Abad Queipo, quien lo aprobó. Miguel se apresuró a suplicar se suspendieran los trámites del embargo proponiendo como vía de pago que se le fuera descontando lo adeudado de los emolumentos de su parroquia. Además marcharía a las haciendas, supuesto origen del problema, para encargarse directamente de ellas y hacerlas producir bien, como había sido la ilusión primera. Abad y Queipo aceptó. ${ }^{37}$

De enero a julio de 1800 estuvo Hidalgo en sus haciendas de Taximaroa. Y fue esa la ocasión, cuando en conversaciones de sobremesa por los días de Pascua, Miguel discutió sobre puntos teológicos y de historia de la Iglesia con dos mercedarios uno de los cuales lo denunciaría a la Inquisición. ${ }^{38}$ En cuanto a la atención directa de

${ }^{36}$ UIA, n. 127 , fs. $32 \mathrm{v}-52$.

${ }^{37}$ El 4 de noviembre de 1797, Miguel Hidalgo pide al colector Lorenzo Bázquez se le espere hasta enero para pago de réditos vencidos. El 31 de enero solicita nueva prórroga, hasta mayo. En mayo, al mismo, dice que no ha mandado "por los contratiempos impensados que me han ocurrido", pero queda "haciendo diligencia con empeño". El 8 de julio de 1797 el colector pide embargo de haciendas de Hidalgo para que pague deuda acumulada de cuatro años: UIA, ns. 172, 178. AEA, caja 19, exp. 15, fs. 362-384, ficha 449.

${ }^{38}$ Pompa, Procesos cit., pp. 9-12. 
las haciendas, parece que logró algo, pero insuficiente para saldar todo lo que adeudaba. ${ }^{39}$ Probablemente fue entonces cuando hizo una venta de ganado de lidia, para las corridas de toros en las fiestas de octubre en San Luis Potosí, adonde se encaminó con su amigo Martín García de Carrasquedo. ${ }^{40}$

A su regreso debió ocurrir algo importante que lo hizo cambiar de manera notoria. A partir de fines de 1800 se acabó el jolgorio en la casa cural de San Felipe, la Francia Chiquita. Redujo los gastos al mínimo, encomendando el manejo del dinero a un vicario "con orden -decía- de que sólo me ministre lo necesario para el plato". ${ }^{41}$ Era palpable la mutación del polifacético párroco, como lo asegura este testimonio: "en el día está haciendo una vida ejemplar en su curato, reducido a la compañía de un solo eclesiástico, retirado de toda tertulia y comercio con las gentes, y entregado al confesionario y demás negocios de su preciso ministerio". Y otro testimonio refiere: "La reforma del cura don Miguel Hidalgo se ha hecho igualmente pública en esta villa, pues he oído hablar de ello a muchas personas de seso". ${ }^{42}$

Tal vez recibió una reprimenda de su hermano Joaquín y de su tío Vicente, e incluso de su máximo protector, el propio obispo. De manera que Miguel tenía que esforzarse por cubrir sus deudas, pero éstas eran demasiadas. Los abonos del préstamo de $\$ 8,000$, la pensión conciliar de la que se le habían juntado $\$ 330$ en $1801,{ }^{43}$ el

${ }^{39}$ El 21 de enero de 1801, el bachiller Juan Olvera, comisionado para descontar de los emolumentos parroquiales de San Felipe el adeudo de Hidalgo, comunica a Lorenzo Bázquez que de los siete meses que estuvo ausente Hidalgo, él estuvo abonando \$100 cada mes; pero a partir de agosto de 1800 de nuevo había adeudo: UIA, n. 178. AEA, caja 19, exp. 15, fs. 362-384, ficha 449.

${ }^{40}$ Pompa, Procesos cit., pp. 46, 24. Según Castillo Ledón, Hidalgo antes de ir a San Luis, había vendido ochenta toros de lidia para corridas en Acámbaro a $\$ 10$ cada uno; pero no aduce documento ni fuente: Luis Castillo Ledón, Hidalgo. La vida del héroe, México, Cámara de Diputados, 1972, 67.

${ }^{41}$ Miguel Hidalgo a Santiago Camińa, explicando que no ha enviado dinero debido a estar cerradas las velaciones matrimoniales, por Adviento, y que él por su parte ha recortado gastos, 10 de diciembre de 1800: AEA, caja 33, exp. 22, fs. 483-484. Arreguín, Hidalgo cit., p. 107.

42 Testimonio del bachiller Pedro Díaz Barriga, e informe de Francisco Antonio de Unzaga, 13 de abril de 1801: Pompa, Procesos cit., pp. 91, 87.

${ }^{43}$ Gabriel García de Obeso informa de esta deuda al Provisor Juan Antonio de Tapia, 
subsidio de la Santa Cruzada, y en espera, como espada de Damocles, las cuentas del Colegio, a cuya segunda revisión aún no respondía; aparte, ahora llegaba el reclamo de lo que había quedado a deber en Colima: $\$ 1,750 ;{ }^{44}$ pero lo peor era que por 1800 había sido fiador de un X Aguirre por cantidad de alrededor de \$10,000 frente a Ignacio Soto Saldaña, ${ }^{45}$ quien logró para su pago que por vía ejecutiva la mitra de Valladolid secuestrara anualmente la tercera parte de los emolumentos del cura de San Felipe. ${ }^{46}$

Así las cosas, la muerte sorprendió a su hermano Joaquín en 1803. ${ }^{47}$ Miguel entonces dejó San Felipe y se hizo cargo interinamente de la parroquia de Dolores, donde no encontró comprobantes por \$6,609 que Joaquín había tomado de la fábrica espiritual de la parroquia para obras de la misma. La mitra acordó que el alcance se fuera pagando con los novenos decimales adeudados al propio Joaquín. ${ }^{48}$ En 1804, Miguel, siendo ya cura propio de Dolores, beneficio algo mejor que San Felipe, esto es, de más de \$4,000 netos, tal vez pensó que tendría mayor solvencia, y así lo vemos comprometiéndose, por una parte, a ayudar con $\$ 200$ anuales a un fraile mercedario que quería secularizarse y, por otra, figurando de fiador por $\$ 1,000$ de su amigo Martín García, que se iba de viaje a Europa. ${ }^{49}$

Respecto a las cuentas del Colegio, Miguel daba largas, pues nunca instruyó a su apoderado, de manera que nombró a otro para que en unión de su tío Vicente, canónigo penitenciario, llegaran a un arreglo con el Colegio; pero como el tío estaba muy enfermo y

quien dispone se envíe carta conminatoria a Hidalgo, 23 de mayo de 1801: Arreguín, Hidalgo cit., pp. 111-112.

${ }^{44}$ María Juliana García, vecina de Colima, pide al obispo obligue a Hidalgo le pague deuda de \$1,000, 18 de octubre de 1799: uia, n. 180. José Felipe Islas, cura de Colima, informa al secretario Rafael Crespo de la deuda a Gregorio Aguirre, $\$ 600$, y a la cofradía de la Soledad, \$150, 19 de febrero de 1801: ACAD, caja 119.

${ }^{45}$ Archivo Complementario, Catedral de Morelia, caja 1544.

${ }^{46}$ Secuestro mencionado en disposición del Provisor Tapia; Arreguín, Hidalgo cit., pp. 111-112.

${ }^{47}$ Archivo Parroquial de San Miguel de Allende (en adelante APSMA), Libro de entierros de españoles, 1786-1810, foja anexa a la 161.

${ }^{48}$ UIA, n. 208.

${ }^{49}$ Pérez, Aspectos cit., pp. 148-151, 155-158. 
murió pronto, se tuvo que rehacer el poder. Finalmente en 1805 , Hidalgo reconoció que debía \$1,000 al Colegio, de los \$7,069 que le cargaban, y que estaba dispuesto a pagarlos de los emolumentos de su curato. El Cabildo aceptó y nombró a un vicario de Dolores hiciera los descuentos de la cantidad adeudada, advirtiéndole ministrase "a dicho párroco en el intermedio tiempo la [cantidad] que califique necesaria para su subsistencia" ${ }^{50}$ Por otra parte es probable que poco después Miguel haya saldado la deuda de los $\$ 8,000$ prestados para las haciendas, sobre las cuales tomó una sensata decisión: rentarlas. Quedaba, empero, el adeudo de los $\$ 7,000$ que por fortuna se pudo ir renovando, pero cuyo pago de réditos se atrasaba. De algunas deudas de los días de San Felipe se había liberado, como la pensión conciliar, pero ya le urgían las correspondientes a Dolores, ${ }^{51}$ en especial el subsidio de la Santa Cruzada, por \$1,302, para lo cual solicitó se le adelantasen los proventos del cuarto noveno decimal. ${ }^{52}$

Cercado por las deudas, pero no derrumbado, así escribió a uno de sus acreedores, Miguel García de Obeso:

usted mejor que nadie sabe las circunstancias en que me hallo; pero éstas no han de ser perpetuas, y componiéndose el curato, como es regular que suceda este año, le satisfaré a usted todo. Hágale usted este favor a una persona que se ve oprimido de las adversidades; pero que los sentimientos son enteramente contrarios a los que la suerte hace lo tengan [a] él. ${ }^{53}$

Ocurrió entonces una disputa entre los acreedores de Miguel. El Comisario de la Santa Cruzada había tramitado el descuento para pago de los \$1,302 que adeudaba Hidalgo; pero el provisor Juan Antonio de Tapia, presionado por Ignacio Soto Saldaña, acreedor por más de $\$ 10,000$, ordenó que de lo secuestrado a Miguel prime-

5014 de marzo de 1805: Acc, Morelia, Libros de Actas, 42, fs. 30-30v.

${ }^{51}$ Miguel Hidalgo a Gabriel García de Obeso, 18 de enero de 1805: ACM, Gastos y cuentas del convento de Santa Catalina de Sena, legajo 11.

${ }^{52} 10$ y 21 de enero de 1806: ACAD, 22.0.01.22, pp. 219-222. 22 de enero de 1806: AEA, caja 19, exp. 15, fs. 362-384.

${ }^{53}$ Miguel Hidalgo a Gabriel García de Obeso, 3 de octubre de 1805: ACM, Gastos y cuentas del convento de Santa Catalina de Sena, legajo 11. 
ro se le pagasen a Soto $\$ 1,084$. Mas por encima del provisor prevaleció el Comisario, apoyado por el contador real y argumentando que el interés del rey era prioritario. ${ }^{54}$

Por si fuera poco, en junio de 1807 , como un rayo recibió $\mathrm{Mi}$ guel la notificación que en virtud de la cédula real de consolidación de vales reales debía aprontar el depósito de los $\$ 7,000$, cuyo plazo de segunda renovación había vencido. El cura de Dolores solicitó se le extendiera el término para presentarse a negociar el pago, pues se hallaba enfermo. Más lo estaba su hermano Manuel, que había entrado en estado de demencia. Pero la respuesta del asesor Terán al subdelegado fue que se procedería al embargo de las haciendas, de no presentarse el cura en diez días por sí o por apoderado y advirtiéndole "que en lo sucesivo no admita semejantes respuestas [la de pedir prórroga por enfermedad], que sólo conspiran a divertir el tiempo, dando ocasión a dilaciones y actuaciones inútiles”. De tal suerte, Miguel contestó que no tenía para pagar ni todo ni nada y que la Junta de Consolidación hiciese lo que tuviera a bien, el embargo naturalmente; pero Miguel se ingenió para que eso tardara, negando facultad al subdelegado de Taximaroa para obligarlo a nombrar evaluador. Finalmente se hizo el avalúo y el embargo. Pero no fueron subastadas, ya que se suspendió la cédula de consolidación. Y así, se procedió al desembargo a fines de $1809 .{ }^{55}$ Como sea, Miguel tuvo que pagar $\$ 243$ de costas del embargo y desembargo, más el viaje de su hermano Mariano para que recibiera la finca. No estuvo Manuel, pues había muerto al filo del embargo.

Y mientras tanto continuaba proyectándose la sombra del hermano Joaquín, pues según el fiscal de la mitra, de los $\$ 6,609$ que resultaron en su contra por falta de comprobantes, sólo se habían cobrado de sus novenos $\$ 3,226$ y por ello aún quedaban $\$ 3,383$ por pagar, en tal forma el fiscal concluía que Miguel debía remitir ese faltante o, bien, presentar "lista de los bienes que quedaron por fallecimiento de su hermano y cuenta jurada de la inversión que les ha

${ }^{54}$ ACAD 22.0.01.22, pp. 221,218, 231, 229-229v.

${ }^{55}$ David A. Brading, "La situación económica de los hermanos don Manuel y don Miguel Hidalgo y Costilla, 1807”, Boletín del AGN, enero-junio 1970, xI, ns. 1-2, pp. 23-75. 
dado, como también del dinero que haya percibido y de las deudas que tenía contraídas, para en su vista promover la exacción como corresponda". ${ }^{56}$

Miguel se apresuró a protestar ante el nuevo obispo Marcos Moriana, aclarando que los novenos pendientes de su hermano, de los que se había de cobrar la deuda, ascendían a $\$ 6,300$, de manera que el adeudo quedaba en sólo $\$ 309$ que él se comprometía a pagar, ya que los bienes de Joaquín "no alcanzaban -dijo-a cubrir los demás créditos a que quedaron afectos, como todo se advierte del adjunto testimonio que en comprobación paso a las superiores manos de vuestra señoría ilustrísima. En este concepto me ha sorprendido ver que el promotor fiscal pida se me reconvenga". ${ }^{57}$ Abad y Queipo ya en su papel de provisor y vicario general, conoció del asunto. $\mathrm{Y}$ al parecer ahí quedó. Por lo demás, Miguel cubría puntualmente unas pequeñas deudas de Joaquín al seno de la cofradía de nuestra Señora de los Dolores. ${ }^{58} \mathrm{Y}$ presionado como todos los demás beneficiados, hubo de contribuir con los donativos forzosos que exigía el gobierno para sostener la guerra en España. Así aparece su nombre en una Gazeta de 1809 con el aporte de $\$ 50$.

Finalmente Miguel no pudo evitar el secuestro total de sus propios novenos decimales. Alegó que la costumbre era no secuestrar más de la tercera parte. ${ }^{59}$ Pero en marzo de 1810 , habiéndose acumulado de ese beneficio parroquial $\$ 8,739.1$, correspondientes a los años de 1804 a 1807, fueron repartidos así entre sus acreedores: $\$ 1,302.1$ para el subsidio de la Santa Cruzada; $\$ 791$ para la familia de su difunto tío Vicente Gallaga; \$1,357.7 a Rafael Crespo cura de San Felipe; \$236.7 a su primo el bachiller Rafael Aragón, y la más fuerte, $\$ 5,051$ a Ignacio Soto Saldaña. ${ }^{60}$ Como se advierte, ya no parecen otros adeudos que tal vez se fueron solventando de las obvenciones parroquiales, que ascendían anualmente a alrededor de $\$ 4,000$ y que a partir de algún momento fueron administradas por

\footnotetext{
${ }^{56}$ Valladolid, mayo de 1809: AEA, caja 23, exp. 19, fs. 154-156, ficha 611.

${ }^{57}$ UIA, n. 208.

${ }^{58}$ AEA, caja 7, exp. 1, fs. 1-151, ficha 153.

${ }^{59}$ UIA, n. 230.

${ }^{60} 27$ y 28 de febrero de 1810: ACAD 22.01.22, pp. 228-230. UIA, n. 228.
} 
el vicario bachiller Francisco Bustamante, ${ }^{61}$ a quien Miguel había entregado la atención de la parroquia, pagándole sin duda algo más que su sueldo de vicario.

Esa entrega de la administración parroquial, sin dejar el beneficio ni la responsabilidad última, permitió a Miguel dedicarse a las actividades de horticultor y artesano, calculando muy probablemente que eso le redituaría más que los emolumentos parroquiales y proporcionaría trabajo a algunos de los desheredados dolorenses. Al efecto dispuso de inmuebles de obras pías de la Iglesia: una casa y tres huertas. ${ }^{62}$ Hay testimonios sobre el éxito. Abad y Queipo dice que Hidalgo emprendió con buen suceso el plantío de moreras para seda, aunque en pequeño, ${ }^{63}$ y Lucas Alamán afirma que Hidalgo

se aficionó a la lectura de obras de artes y ciencias y tomó con empeño el fomento de varios ramos agrícolas e industriales en su curato. Extendió mucho el cultivo de la uva [...] y propagó el plantío de moreras para el cultivo del gusano de seda [...] Había además formado una fábrica de loza, otra de ladrillos, construido pilas para curtir pieles e iba estableciendo talleres de diversas artes [...] había conseguido muchos adelantos hasta hacer con la seda de sus cosechas algunas piezas de ropa para su uso y el de la señora última esposa de su padre. Había aumentado también la cría de abejas $[\ldots]^{64}$

Pero Alamán estaba errado en la asignación de la renta del curato de Dolores, al estimarla en ocho o nueve mil pesos anuales; puesto que tal renta era en realidad de alrededor de $\$ 6,000$, integrada por dos rubros: los cuatro novenos decimales y las obvenciones parroquiales. La participación en el diezmo, en promedio anual, entre 1804 y 1810 , fue de $\$ 2,000$, y las obvenciones parroquiales producían unos $\$ 4,000$, de los cuales había que descontar los pagos de

${ }^{61}$ El propio Hidalgo lo afirma así: UIA, n. 230. Alamán dice que la entrega fue a Francisco Iglesias: Alamán, Historia, cit., I, p. 226.

${ }^{62}$ Archivo General del Estado de Guanajuato (en adelante AGEG), Ramo Notarías. Libro de Notarías de Dolores Hidalgo. Libro bianual 1822-1823, fs. 65-67, 70.

${ }^{63} 12$ de febrero de 1810: Arreguín, Hidalgo cit., pp. 131-133.

${ }^{64}$ Alamán, Historia cit., pp. 226-227. 
vicarios y de otro personal, probablemente cerca de $\$ 2,000$; de manera que los ingresos netos del cura llegarían a algo más de $\$ 4,000$ al ańo, como sea, un beneficio pingüe, equivalente a unos cincuenta y cinco salarios anuales de un peón jornalero.

Sin embargo, de los novenos decimales no percibió nada de lo correspondiente a cuatro años de 1804 a 1807, secuestrados como estuvieron, y de las obvenciones probablemente no siempre recibió los $\$ 2,000$ señalados, puesto que al menos en algunos años fueron intervenidas para pago de deudas y luego se disminuyeron por la concesión que hizo de la administración parroquial.

Para el requerimiento de la pensión conciliar, en que otra vez se había atrasado por $\$ 645$ en mayo de 1810, Hidalgo dio largas, contestando que para tal pago había notificado al canónigo Betancourt lo hiciera, puesto que le adeudaba a Miguel unos réditos. ${ }^{65}$ Probablemente los pagó el prebendado por agosto, ya que a la vuelta de dos meses, al aproximarse el cura a Valladolid, transformado en capitán general de insurgentes, el canónigo Betancourt fue de los comisionados a entrevistarse con él y no recibió el maltrato dado a otros capitulares ${ }^{66}$ Por lo demás, el caudillo no aprovechó las estancias en Valladolid para saldar cuentas pendientes haciendo que desaparecieran documentos o presionando para imponer un arreglo. En realidad ya no eran muchas ni considerables, salvo la de Soto Saldaña.

En efecto, de todo lo dicho hay elementos para decir que en vísperas del Grito Miguel Hidalgo iba saliendo de la mayor parte de sus deudas no sin dificultad, pero de la propensión a buscar préstamos no se había curado. La misma noche del 15 de septiembre obtuvo $\$ 200$ del colector de diezmo de Dolores. ${ }^{67}$

${ }^{65}$ Valladolid, 26-28 de mayo, 13-14 de junio de 1810; Dolores, 27-3º de junio de 1810; Valladolid, julio 4 y 9; Dolores, 20 de julio de 1810: Archivo Complementario Catedral de Morelia, caja 17, exp. 42.

${ }^{66}$ Moisés Guzmán Pérez, Miguel Hidalgo y el gobierno insurgente en Valladolid, Morelia, UMSNH, 2003, 133-139.

${ }^{67}$ Alamán, Historia cit., I, p. 240. 


\section{RECAPITULACIÓN Y REFLEXIONES CONCLUSIVAS}

Podemos advertir cuatro rubros en que se pueden agrupar las principales deudas de Hidalgo. El primero, el de las haciendas de Taximaroa, por dos depósitos de un total de $\$ 15,000$ más los réditos. Hacia 1805 se había liberado el depósito de \$8,000. En dos ocasiones estuvieron en riesgo de ser enajenadas por insolvencia: la primera por réditos vencidos y la segunda por el sorpresivo apremio del capital de $\$ 7,000$. Finalmente quedó en una deuda de réditos que se pagaban regularmente gracias al arrendamiento. Y aunque tenían riego, la falta de una atención directa y constante por parte de los propietarios Hidalgo no les había permitido hacer de ellas un buen negocio. A pesar de todo, consumada la Independencia, quedarían en propiedad de la sucesión de Manuel Hidalgo. ${ }^{68}$

La segunda deuda es el alcance por la administración de la tesorería del Colegio de San Nicolás por \$7,069, de los que Hidalgo sólo reconoció $\$ 1,000$, que finalmente fueron saldados. Aquí afloran dos cosas: la esplendidez de Miguel con los estudiantes y el enigma de Manuel Iturriaga, el promotor de esa acción contra Hidalgo, pues se trata del mismo personaje que conforme a fray Servando y al doctor Mora fue el alma de la conspiración de Querétaro y su delator en artículo de muerte. ${ }^{69}$ ¿Tomó acaso esta decisión al enterarse que Hidalgo se adhería a ella y era nombrado jefe?

En tercer lugar, las contribuciones eclesiásticas al Seminario Conciliar y al Colegio de las Rosas, así como las mesadas y los subsidios para la Corona, todo en razón de los beneficios eclesiásticos que disfrutó, esto es, tres parroquias, dos sacristías y una capellanía. Fueron sucesivos; y cuyas pensiones, pagadas regularmente, no representaban montos asfixiantes, pero acumuladas y agregadas a los réditos vencidos, en dos ocasiones condujeron a Hidalgo a un

${ }^{68}$ AGN, Archivo Judicial, caja única, exp. 1, Testamentaría de Manuel Hidalgo.

${ }^{69}$ José Guerra [Fray Servando Teresa de Mier], Historia de la revolución de Nueva España, I, Londres, Guillermo Glindon, 1813, 292 (Ed. facsímil México, Instituto Mexicano del Seguro Social, 1980). José María Luis Mora, México y sus revoluciones, III, México, Porrúa, 1965, 20-28. 
recorte de gastos en que sólo se le administraba para el plato. Al parecer en los últimos ańos de Dolores se pagaban, pero no sin atrasos.

En cuarto lugar, la deuda más cuantiosa a Soto Saldaña, por encima de $\$ 10,000$, y la menos documentada en sus orígenes. Al parecer contraída por haber sido fiador de alguien insolvente. Este adeudo, unido a los otros, fue el causante principal del secuestro de los novenos decimales de cuatro años. Saldada en $50 \%$ al momento del Grito, sería cubierta veinte años más tarde con una casa de la mitra en Morelia, gracias a los novenos decimales de los últimos tres años de Hidalgo en Dolores. ${ }^{70}$

Para Miguel el gastar con esplendidez en regocijo de muchos, así como en emprender inversiones ya riesgosas, como las haciendas, ya exitosas, como las artesanías, fue parte normal de su existencia, bien que se echara a cuestas graves deudas que se le iban venciendo. A tal grado le parecía normal, que no obstante algunos momentos de preocupación por tales situaciones, no lo abrumaban, pues se las ingeniaba para dar largas a los acreedores, así como para salir de unas deudas contrayendo otras, y limitarse por unos días para luego volver a gastar. De tal manera, no le quitaron el gusto por la vida, "la suma alegría” que le advertían algunos contemporáneos, así fuera gastando lo que debía, sin hacer caso de requerimientos.

Pero se trata de una visión incompleta. No era solo Miguel Hidalgo el endeudado. No pocos habitantes de la Nueva España eran empujados a la situación de vivir de prestado y asediados por los acreedores. Otros de los futuros dirigentes de la insurgencia, como Allende, Rayón, Morelos y Berdusco, aparecen con deudas, algunas que podemos llamar regulares, pero otras vencidas. Aparte a Hidalgo tampoco le entregaban oportunamente dinero que le correspondía.

Ignacio Allende había pedido prestado de los fondos del convento de Santa Catalina de Siena de Valladolid, bien que según parece ya lo había pagado a la hora del Grito. ${ }^{71}$ Ignacio Rayón había adqui-

\footnotetext{
${ }^{70}$ UIA, n. 228.

${ }^{71}$ ACM, Gastos y cuentas del convento de Santa Catalina de Sena, legajo 11.
} 
rido derechos sobre una mina de Tlalpujahua con la obligación de contribuir a los gastos de su funcionamiento, pero en junio de 1809 suspendió temporalmente toda contribución, "por hallarme absolutamente sin reales", y pidiendo se esperase a que tuviera solvencia; pero el otro accionista de la mina, el peninsular Juan Santos de Pazos, no lo admitía y exigía en octubre el pago de 930 pesos. Rayón entonces prolongó el pleito exigiendo que Santos exhibiera formalmente sus derechos a la mina. Así llegó el día del Grito y de la incorporación de Rayón a la lucha. ${ }^{72}$

José María Morelos para poderse sostener en la magra parroquia de Carácuaro Nocupétaro y llevar a cabo una serie de mejoras en ella, hubo de emprender negocios de comercio en unión de su cuñado Cervantes residente en Valladolid, lo cual requería crédito. De tal manera lo solicitó y obtuvo de Pacual Alsúa, comerciante destacado de Valladolid, a quien Morelos debía 673 pesos en mayo de 1810. En vez de liquidarlos, le pidió más, hasta completar mil pesos, hipotecando ahora su casa de Valladolid, a razón del cinco por ciento anual "y por el tiempo en que más pronto pueda pagar dicha cantidad". ${ }^{73}$

José Sixto Berdusco, arrastraba deudas desde 1799, a raíz de haber arrendado los diezmos de Tlazazalca y La Piedad, de lo que debía 20,175 pesos. Ostentaba doctorado en teología; fue catedrático, vicerrector y rector del Colegio de San Nicolás. Desempeñando este cargo en 1804 pidió préstamo al mismo colegio por 500 pesos, e hipotecó sus bienes. Buscó beneficios jugosos, pero lo que más obtuvo fue el magro de Tuzantla, de donde saldría para la insurgencia. $^{74}$

${ }^{72}$ Archivo Municipal de Tlalpujahua (en adelante Aмт), exp. s/n: Juan Santos de Pazos contra domingo Fernández Moreno e Ignacio Rayón sobre pago de rayas o adjudicación de cinco barras de la mina La Concepción, 1809-1820, 59 fs. He reseñado el pleito completo en: Carlos Herrejón Peredo, La Independencia según Ignacio Rayón, México, Secretaría de Educación Pública (en adelante SEP), 1985, 259-265.

${ }^{73}$ Archivo de Notarías, Morelia (en adelante ANM), Notario José María Aguilar, vol. 222, fs. 264v-268. Carlos Herrejón Peredo, Morelos. Vida preinsurgente y lecturas, Zamora, El Colegio de Michoacán, 1984, 227-230.

${ }^{74}$ Moisés Guzmán Pérez, Tuzantla. Historia en la Tierra Caliente, Morelia, Morevallado, 1991, 50-51. 
No se diga de deudas de las castas y los indios. Según Benito Díaz de Gamarra en la región de San Miguel el Grande había muchos en prisión por deudas, de donde los sacaba la caridad de Felipe Neri de Alfaro. ${ }^{75}$

A la luz de lo dicho adquiere mayor significado una de las disposiciones del primer bando de Morelos. Dice así: "Todo americano que deba cualquiera cantidad a los europeos, no está obligado a pagarla; y si fuere lo contrario, el europeo será ejecutado a la paga con el mayor rigor" ${ }^{76}$

Está por averiguar con precisión el grado de endeudamiento no tanto como rasgo peculiar de algunos caudillos, sino como algo muy generalizado en los criollos, insurgentes o realistas, e inclusive peninsulares sujetos a reformas y procesos económicos del tiempo. Personajes de altos ingresos como las dignidades del cabildo catedral de Valladolid comenzando por el mismo deán Juan Antonio de Tapia, también arrastraban deudas al término del siglo, provenientes de la fiscalización creciente de la Corona. ${ }^{77}$ Mas parece que al que menos le preocupaba su endeudamiento personal era al propio $\mathrm{Hi}$ dalgo, cuyo carácter espléndido y pródigo chocaba con el de no pocos gachupines a quienes reprochaba la avaricia como razón última de los principales agravios y una forma de idolatría: "No son católicos sino por política; su dios es el dinero". ${ }^{78}$

La burocracia ya civil, ya eclesiástica, estaba presionada para recabar y exigir, tanto más cuanto que frecuentemente sus ingresos estaban en función de lo que cobrasen. Hemos visto que algunos episodios del endeudamiento de Hidalgo están marcados por ese

${ }^{75}$ Juan Benito Díaz de Gamarra, El sacerdote fiel y según el corazón de Dios. Elogio fúnebre que en las magnificas exequias celebradas el dia 22 de abril de 1776 en el santuario de Jesús Nazareno de Atotonilco a su patrón y fundador el P. D. Luis Felipe Neri de Alfaro [...] dixo [...], México, Joseph de Jáuregui, 1776, 46.

${ }^{76}$ Ernesto Lemoine Villicaña, Morelos. Su vida revolucionaria a través de sus escritos y de otros testimonios de la época, México, unAM, 1965, 162.

${ }^{77}$ Juvenal Jaramillo, tesis doctoral "Los capitulares y el Cabildo Catedral de Valladolid-Morelia. 1790-1833. Auge y decadencia de una institución eclesiástica”, El Colegio de Michoacán, 2012.

${ }^{78}$ Manifiesto, Valladolid, 15 de noviembre, en Alamán, Historia cit., II, p. 392; Hernández, Colección cit., I, p. 125. 
afán de burócratas o acreedores puntillosos y extremadamente exigentes, como en el asunto de las cuentas del Colegio, en el de la consolidación y en el adeudo de su hermano Joaquín. Sin duda que formaron parte del malestar que privaba en Nueva España y predispusieron a Hidalgo en su repulsa del estado de cosas; pero no creo que tales circunstancias -sólo comprobadas en algunas de sus deudas- hayan constituido un motivo determinante de su decisión por la insurrección, pues bien sabía el propio Hidalgo que gran parte de los débitos provenían de su prodigalidad y desentendimiento de pagos oportunos. Sólo hubo una deuda que pudo provocarle la indignación extrema: la de la consolidación, en cuanto que su hermano Manuel pudo haber enloquecido por la angustia del cobro de los $\$ 7,000$, capital adeudado de las haciendas. Ciertamente murió demente al filo del embargo el 14 de junio de $1808 .{ }^{79}$ Pero tal relación de causalidad es difícil de probar con certeza, pues las haciendas ya no eran de él, sino de Miguel. ${ }^{80}$

Además, como hemos señalado, parece que al momento del Grito Miguel ya iba saldando la mayor parte de su deuda y él mismo consideraba que, a pesar de ello, llevaba una existencia apacible, pues dijo que de no haber tomado las armas, "disfrutaría de una vida dulce, suave y tranquila" ${ }^{81}$ Por todo lo dicho no se sostiene una apreciación de la economía de Hidalgo en que la generalidad de sus acreedores se hacen aparecer como despiadados burócratas o voraces usureros, e Hidalgo como el héroe inmaculado a todo trance.

Las conductas derivadas del carácter pródigo de Hidalgo se inscribían y agudizaban en circunstancias de reformas y crisis económicas. A partir de los tiempos en que asumió la parroquia de San Felipe, esto es la década de los noventa, la monarquía española transitaba de una época marcada por el reformismo a otra en que continuaron las reformas, pero adicionadas con un acelerado proceso de

${ }^{79}$ AGN, Archivo Judicial, caja única, exp. 1, Testamentaría de Manuel Hidalgo, f. 20.

${ }^{80}$ Debo aquí corregir lo que escribí hace años en torno a este episodio, dando entonces por sentada la relación entre la demencia y muerte de Manuel con la opción revolucionaria de Miguel: Carlos Herrejón Peredo, Hidalgo antes del Grito de Dolores, Morelia, UMSNH, 1992, 35.

${ }^{81}$ Hernández, Colección cit., I, p, 125. 
endeudamiento por guerras internacionales, que fue llevando a la bancarrota. Marichal y otros han señalado cómo la Nueva España participó destacadamente en tal proceso, como una de las principales fuentes de financiamiento de la monarquía. Esto implicaba una política de exacción creciente, tanto por vía tributaria, como de préstamos y donativos forzosos, hasta llegar a la extracción de capitales. Así, la generalidad del país estaba endeudado como parte de la bancarrota de la monarquía. ${ }^{82}$

\section{FUENTES MANUSCRITAS}

ACAD: Archivo Capitular de Administración Diocesana, Catedral de Morelia.

ACC: Archivo Capitular, Catedral de Morelia, Mich.

ACM: Archivo Casa de Morelos, INAH, Morelia, Mich.

AEA: Archivo Enrique Arreguín, México, D. F. (particular).

AGEG: Archivo General del Estado de Guanajuato, Guanajuato,

Gto.

AGN: Archivo General de la Nación, México, D. F.

AMT: Archivo Municipal de Tlalpujahua, Mich.

ANM: Archivo de Notarías, Morelia, Mich.

APSMA: Archivo Parroquial de San Miguel de Allende, Gto.

BPU: Biblioteca Pública Universitaria, Morelia, Documentos de Hidalgo.

UIA: Universidad Iberoamericana, México, D. F., Biblioteca Francisco Xavier Clavigero, Archivo de don Miguel Hidalgo y su familia.

\section{Publicadas}

Alamán, Lucas, Historia de México, México, Jus, 1942.

AmaYA, Jesús, El Padre Hidalgo y los suyos. Genebiografía del héroe, sus antepasados y parientes, México, Lumen, 1952 (Ed. facsímil Mo-

${ }^{82}$ Carlos Marichal, La bancarrota del virreinato. Nueva España y las finanzas del imperio español, 1780-1810, México, El Colegio de México, Fondo de Cultura Económica, 1999. 
relia Universidad Michoacana de San Nicolás de Hidalgo, 2002).

Arreguín, Enrique, Hidalgo en San Nicolás. Documentos inéditos, Morelia, Fímax, 1956.

Boletín del Archivo General de la Nación, México, julio-septiembre, t. xviı, núm. 3, 1946, 372-379.

Brading, David A., "La situación económica de los hermanos don Manuel y don Miguel Hidalgo y Costilla, 1807", Boletín del Archivo General de la Nación, México, XI, núms. 1-2, enero-junio 1970, 23-75.

Castillo Ledón, Luis, Hidalgo. La vida del héroe, México, Cámara de Diputados, $1972 .{ }^{83}$

DÍAZ DE GAMARRA, Juan Benito, El sacerdote fiel y según el corazón de Dios. Elogio fúnebre que en las magnificas exequias celebradas el dia 22 de abril de 1776 en el santuario de Jesús Nazareno de Atotonilco a su patrón y fundador el P. D. Luis Felipe Neri de Alfaro [...] dixo [...], México, Joseph de Jáuregui, 1776.

Florescano, Enrique y Rodolfo PAstor, Fuentes para la historia de la crisis agricola de 1785-1786 (Selección documental), México, Archivo General de la Nación, México, II, pp. 892-893.

Guerra, José [Fray Servando Teresa de Mier], Historia de la revolución de Nueva España, Londres, Guillermo Glindon, 1813 (Ed. facsímil México, Instituto Mexicano del seguro Social, 1980).

GuzMán PÉRez, Moisés, Miguel Hidalgo y el gobierno insurgente en Valladolid, Morelia, Universidad Michoacana de San Nicolás de Hidalgo, 2003.

, Tuzantla. Historia en la Tierra Caliente, Morelia, Morevallado, 1991.

Hernández y Dávalos, Juan E., Colección de documentos para la guerra de independencia de México de 1808 a 1821, México, 1877-1882.

${ }^{83}$ De propósito casi no he citado esta obra, a pesar de que contiene pistas valiosas, porque he tenido acceso a las fuentes directas que utilizó el autor y a otras muchas manuscritas que él no tuvo oportunidad de conocer. Por lo demás, el enfoque es muy diverso: no trato de escribir la vida del héroe, sino sólo seguir el endeudamiento del hombre, en lo cual aún quedan no pocas cosas por aclarar, precisar y corregir. 
Herrejón Peredo, Carlos, Hidalgo antes del Grito de Dolores, Morelia, Universidad Michoacana de San Nicolás de Hidalgo, 1992. , La Independencia según Ignacio Rayón, México, Secretaría de Educación Pública, 1985.

Ibarra Grande, Jesús, Don Miguel Hidalgo y Costilla y Gallaga, cura de la Villa de San Felipe, Guanajuato, Archivo General del Estado de Guanajuato, 2003.

Lemoine Villicaña, Ernesto, Morelos. Su vida revolucionaria a través de sus escritos y otros testimonios de la época, México, Universidad Nacional Autónoma de México, 1965.

Marichal, Carlos, La bancarrota del virreinato. Nueva España y las finanzas del imperio español, 1780-1810, México, El Colegio de México, Fondo de Cultura Económica, 1999.

Mora, José María Luis, México y sus revoluciones, México, Porrúa, 1965.

Pérez Escutia, Ramón Alonso, Aspectos de la vida preinsurgente de Hidalgo, Morelia, Universidad Michoacana de San Nicolás de Hidalgo, 1991.

Pompa y Pompa, Antonio, Procesos inquisitorial y militar seguidos a D. Miguel Hidalgo y Costilla, México, Instituto Nacional de Antropología e Historia, 1960.

FECHA DE RECEPCiÓn DEL ARTículo: 28 de febrero de 2011

FeCHA DE RECEPCIÓN DE LA VERSIÓN FINAL: 5 de abril de 2011 